\title{
Porfirias Agudas: Aspectos Laboratoriais
}

\author{
Carlos André Prauchner', Tatiana Emanuelli1,2* \\ ${ }^{1}$ Centro de Ciências Naturais e Exatas, ${ }^{2}$ Departamento de Tecnologia e Ciência dos Alimentos, Centro de Ciências \\ Rurais, Universidade Federal de Santa Maria, Santa Maria, RS, Brasil
}

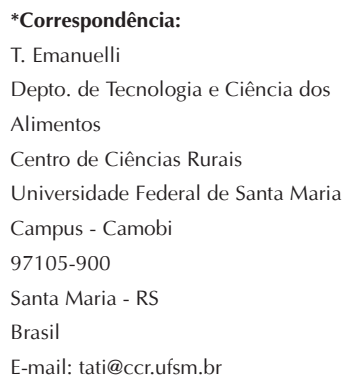

\section{INTRODUÇÃO}

As porfirias são doenças hereditárias ou adquiridas, caracterizadas por deficiência parcial na atividade de uma das enzimas da via de biossíntese do grupo heme (Figura 1), o que leva à diminuição dos níveis deste grupamento e ao acúmulo de seus precursores metabólicos (Kappas et al., 1995). Nos casos de porfirias adquiridas, a deficiência na
As porfirias são causadas por deficiência parcial de uma das enzimas da via de biossintese do heme, caracterizando-se por disfunções neuroviscerais bastante semelhantes. As porfirias agudas são decorrentes da deficiência das enzimas deltaaminolevulinato desidratase (ALAD), porfobilinogênio desaminase, coproporfirinogênio oxidase ou protoporfirinogênio oxidase, que provocam, respectivamente, porfiria por deficiência da ALAD, porfiria aguda intermitente, coproporfiria hereditária e porfiria variegada. Todas as porfirias agudas caracterizam-se por um aumento na concentração de ácido 5-aminolevulínico no plasma e no líquor, acompanhado de um aumento na excreção urinária deste composto. Dependendo do tipo de porfiria aguda que acomete o paciente, podem ser observados ainda aumentos na excreção urinária de outros precursores porfirínicos e mesmo de porfirinas. Os casos de porfirias agudas podem ser detectados pela dosagem de porfirinas e seus precursores na urina, sangue e fezes. A triagem das famílias portadoras é importante para detectar casos latentes, pois a expressão clínica da doença geralmente está ligada a fatores ambientais ou adquiridos que provocam os ataques agudos. A identificação de portadores pode ser realizada através da determinação da atividade das enzimas da via de biossíntese do heme no sangue e mais recentemente através da análise do DNA.
Unitermos:

- Porfirias agudas

- Ácido 5-aminolevulínico

- Porfirinas

- Porfobilinogênio

- Mutações via de biossíntese do grupo heme pode ocorrer devido à ação inibitória de metais pesados, tais como chumbo (Rocha et al., 1995), mercúrio (Rocha et al., 1993; Emanuelli et al., 1996) e selênio (Barbosa et al., 1998), ou de herbicidas (Krijt et al., 1997) sobre enzimas desta via. Nos casos de porfirias hereditárias, a deficiência é genética e pode afetar qualquer das enzimas da rota, com exceção da primeira (Figura 1; Kappas et al., 1995). 


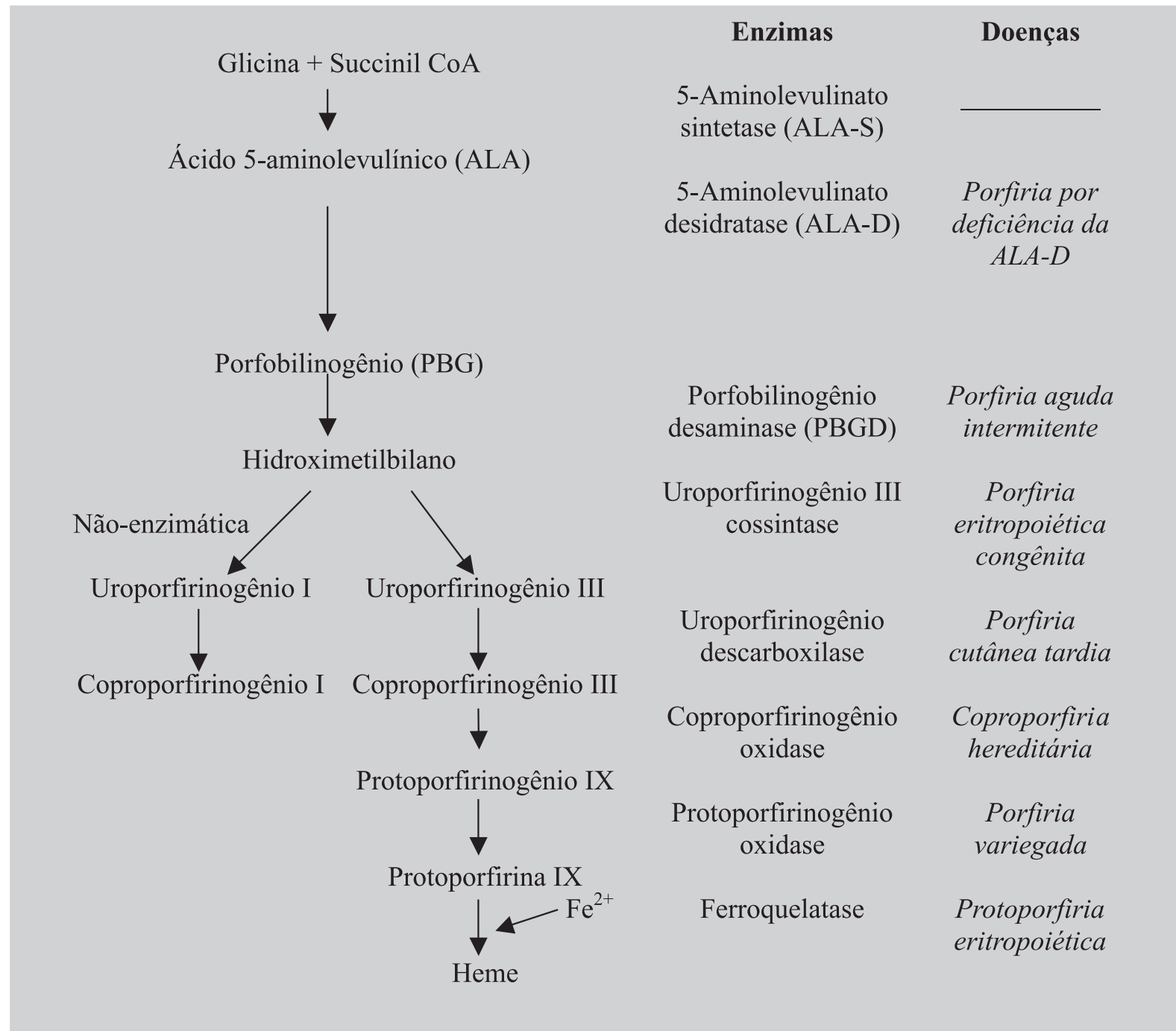

FIGURA 1- Via de biossíntese do grupo heme e porfirias hereditárias associadas a deficiências em enzimas específicas desta via.

Fonte: Anderson, 1992. Obs: A primeira enzima da via e as últimas 3 são mitocondriais, enquanto as outras 4 são citosólicas.

As porfirias agudas ocorrem em todas as raças. A prevalência estimada na maioria dos países da Europa é de 1-2 por 100000 habitantes (Elder et al., 1997), sendo a porfiria aguda intermitente (PAI) o tipo mais comum. No entanto, observa-se uma prevalência bem maior na população psiquiátrica (210 por 100000 habitantes, nos Estados Unidos), o que foi atribuído a diagnósticos equivocados devido aos sintomas neuropsiquiátricos das porfirias (Tishler et al., 1985).

\section{PORFIRIAS AGUDAS}

\section{Classificação}

As porfirias hereditárias são classificadas como hepáticas ou eritrocitárias de acordo com o principal local de expressão da deficiência enzimática (Tabela I; Kappas et al., 1995). A Tabela I apresenta um resumo dos tipos de porfirias, sua classificação, mecanismo de herança, sintomas característicos e metabólitos acumulados. Quatro tipos de porfirias hepáticas [porfiria aguda intermitente (PAI; Grandchamp, 1998), coproporfiria hereditária (CPH; Martásek, 1998), porfiria variegada (PV; Kirsch et al., 1998) e porfiria por deficiência da 5-aminolevulinato desidratase (PALAD; Gross et al., 1998; Sassa, 1998)] são classificadas como "porfirias agudas", pois estão associadas a ataques caracterizados por disfunções neuroviscerais idênticas (neuropatia) e produção excessiva dos precursores porfirínicos, ácido 5-aminolevulínico (ALA) 
TABELA I - Classificação e características das principais porfirias humanas

\begin{tabular}{|c|c|c|c|c|c|}
\hline Porfiria & Classificação & Herança & Sintomatologia & Excreção fecal & Excreção urinária \\
\hline $\begin{array}{l}\text { Porfiria } \\
\text { eritropoiética } \\
\text { congênita }\end{array}$ & Eritropoiética & $\begin{array}{l}\text { Autossômica } \\
\text { recessiva }\end{array}$ & Fotossensibilidade & Coproporfirina & $\begin{array}{l}\text { Uroporfirina, } \\
\text { coproporfirina }\end{array}$ \\
\hline $\begin{array}{l}\text { Protoporfiria } \\
\text { eritropoiética }\end{array}$ & Eritropoiética & $\begin{array}{l}\text { Autossômica } \\
\text { dominante }\end{array}$ & Fotossensibilidade & Protoporfirina & Ausente \\
\hline $\begin{array}{l}\text { Porfiria por } \\
\text { deficiência da } \\
\text { ALA-desidratase }\end{array}$ & Hepática & $\begin{array}{l}\text { Autossômica } \\
\text { recessiva }\end{array}$ & $\begin{array}{l}\text { Alterações } \\
\text { neuroviscerais }\end{array}$ & - & $\begin{array}{l}\text { ALA, } \\
\text { coproporfirina III, } \\
\text { protoporfirina }\end{array}$ \\
\hline $\begin{array}{l}\text { Porfiria aguda } \\
\text { intermitente }\end{array}$ & Hepática & $\begin{array}{l}\text { Autossômica } \\
\text { dominante }\end{array}$ & $\begin{array}{l}\text { Alterações } \\
\text { neuroviscerais }\end{array}$ & 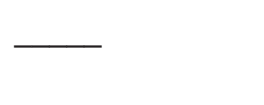 & ALA, PBG \\
\hline $\begin{array}{l}\text { Coproporfiria } \\
\text { hereditária }\end{array}$ & Hepática & $\begin{array}{l}\text { Autossômica } \\
\text { dominante }\end{array}$ & $\begin{array}{l}\text { Alterações } \\
\text { neuroviscerais/ } \\
\text { Fotossensibilidade }\end{array}$ & Coproporfirina & $\begin{array}{l}\text { ALA, PBG, } \\
\text { coproporfirina }\end{array}$ \\
\hline Porfiria variegada & Hepática & $\begin{array}{l}\text { Autossômica } \\
\text { dominante }\end{array}$ & $\begin{array}{l}\text { Alterações } \\
\text { neuroviscerais/ } \\
\text { Fotossensibilidade }\end{array}$ & $\begin{array}{l}\text { Coproporfirina, } \\
\text { protoporfirina, } \\
\text { isocoproporfirina }\end{array}$ & $\begin{array}{l}\text { ALA, PBG, } \\
\text { coproporfirina }\end{array}$ \\
\hline $\begin{array}{l}\text { Porfiria cutânea } \\
\text { tardia }\end{array}$ & Hepática & Variável* & Fotossensibilidade & Isocoproporfirina & $\begin{array}{l}\text { Uroporfirina, } \\
\text { Porfirina 7- } \\
\text { carboxilato }\end{array}$ \\
\hline
\end{tabular}

* A herança autossômica dominante ocorre em algumas famílias, mas não em outras. Fonte: Adaptado de Kappas et al., 1995. Negrito: Porfirias agudas, as quais são acompanhadas de aumentos na excreção de ALA.

e porfobilinogênio (PBG) (Tabela I; Moore, 1993; Meyer et al., 1998).

As porfirias agudas são de herança autossômica dominante, com exceção da PALAD, que possui herança autossômica recessiva (Tabela I). A expressividade das porfirias agudas é variável, sendo que os pacientes podem permanecer assintomáticos durante anos. A expressão clínica da doença geralmente está ligada a fatores ambientais ou adquiridos que provocam os ataques agudos por aumentar a demanda de heme, estimulando a síntese da enzima ALA-S (Moore, 1980; Kappas et al., 1995). O fator predisponente mais importante é a ingestão de medicamentos que sofrem metabolização pelo sistema citocromo $\mathrm{P}_{450}$ (dependente de heme), induzindo a síntese deste complexo enzimático com conseqüente consumo de heme (Moore et al., 1983; De Matteis, 1988).

\section{Alterações Bioquímicas e Diagnóstico}

A deficiência na via de biossíntese do heme, concomitante com a indução da ALA-S, leva a aumento na excreção urinária de ALA (12 a 50 mg/L vs. <1 mg/L em pessoas sadias), bem como na sua concentração no plasma $\left(10^{-3}\right.$ a $10^{-5} \mathrm{M}$ vs. $<10^{-6} \mathrm{M}$ em pessoas sadias) e no líquor $\left(10^{-5}\right.$ a $10^{-7} \mathrm{M}$ vs. $<10^{-8} \mathrm{M}$ em pessoas sadias $)$ dos pacientes (Granick, Van Den Schrieck, 1955; Yeung Laiwah et al., 1987). Dependendo do tipo de porfiria aguda que acomete o paciente são observados ainda aumentos na excreção urinária de outros precursores porfirínicos e mesmo de porfirinas (Tabela I). As diferenças no padrão de excreção destes compostos nos diversos tipos de porfirias são usadas no diagnóstico, juntamente com os sinais clínicos manifestados pelos pacientes.

Além das alterações nos níveis de compostos intermediários da síntese do heme, também foram observados aumentos na concentração plasmática de triptofano e serotonina e redução nos níveis plasmáticos de melatonina (Puy et al., 1993).

Como grande parte dos portadores de genes defeituosos permanecem assintomáticos durante toda a vida, a triagem das famílias portadoras é importante para detectar os casos latentes de porfirias agudas com o objetivo de 
advertir sobre as precauções necessárias à prevenção dos ataques. Os casos latentes podem ser detectados pela dosagem de porfirinas e seus precursores na urina, sangue e fezes, ou pela medida da atividade de enzimas da via de biossíntese do heme. Isoladamente, as dosagens de porfirinas e seus precursores oferecem uma confiabilidade de $50 \%$ ao diagnóstico, contra $95 \%$ obtidos quando estas dosagens forem combinadas com a análise enzimática (McColl et al., 1982).

Para o diagnóstico definitivo de casos de porfiria por deficiência da ALA-D é necessário que seja observada, além dos sinais clínicos e de aumentos na excreção urinária de ALA e porfirinas (Tabela I), uma deficiência da enzima ALA-D em eritrócitos. Esta deficiência pode variar entre 50 e $98 \%$ da atividade enzimática normal (Bird et al, 1979). A determinação de ALA na urina ou no sangue dos pacientes é realizada por cromatografia líquida de alta eficiência com detector fluorimétrico ou eletroquímico (Oishi et al., 1996; Costa et al., 1997).

O diagnóstico da PAI baseia-se na observação de uma atividade da PBGD eritrocitária geralmente 50\% inferior aos valores normais (Kappas et al., 1995). Devido à grande variação nos valores normais de atividade desta enzima, os casos limítrofes são melhor interpretados determinando-se a atividade da PBGD eritrocitária de outros membros da família. Um pequeno subgrupo de pacientes com PAI tem atividade normal de PBGD eritrocitária. Nestes casos, a diminuição da atividade é detectada em cultura de fibroblastos ou de linfócitos (Kappas et al., 1995). A distinção entre pacientes portadores (ou estado latente) e aqueles com PAI expressa clinicamente depende da anamnese e da observação dos aumentos na excreção urinária de PBG e ALA, que ocorrem durante os ataques. O PBG urinário é determinado colorimetricamente pela formação de uma coloração rosa após reação deste composto com o reagente de Erhlich (Mauzerall, Granick, 1956; Galbraith et al., 1987). Resultados falsopositivos foram observados após tratamento com fenotiazinas. Com a recente identificação das mutações existentes na PBGD, a análise de DNA aumentou a exatidão na detecção de heterozigotos assintomáticos em famílias com PAI, permitindo melhor aconselhamento genético (Grandchamp, 1998). Uma característica interessante da urina dos pacientes com PAI é que ela pode apresentar coloração avermelhada após exposição à luz.

A hipercolesterolemia é observada com uma freqüência razoável em pacientes com PAI. Também são observadas várias endocrinopatias nestes pacientes, tais como a síndrome da liberação inadequada do hormônio antidiurético, alterações na liberação do hormônio do crescimento, do hormônio adrenocorticotrófico, hiperinsuline- mia e galactorréia (Perlroth et al., 1967; Waxman et al., 1969; Tschudy et al., 1975; Kappas et al., 1995).

Níveis elevados de ALA e PBG são encontrados também em CPH e PV. Provas bioquímicas adicionais, como a determinação de porfirinas urinárias e fecais, são úteis para distinguir a PAI dessas porfirias que podem produzir ataques semelhantes (Tabela I).

$\mathrm{O}$ diagnóstico de $\mathrm{CPH}$ deve ser considerado em pacientes com sinais característicos de um ataque agudo de porfiria, mas nos quais a atividade da PBGD é normal. Nos pacientes com $\mathrm{CPH}$, a coproporfirinogênio oxidase de leucócitos geralmente apresenta $50 \%$ da atividade normal em heterozigotos e 20 a $10 \%$ em homozigotos. Na ausência da determinação enzimática, o melhor índice para a triagem dos membros da família é a demonstração de coproporfirinas (predominantemente do tipo III) substancialmente elevadas na urina e fezes (Tabela I), que pode ser facilmente verificada pela intensa fluorescência vermelha emitida sob luz ultravioleta (Martásek, 1998). No entanto, um pequeno aumento na coproporfirina urinária é uma alteração comum na via de biossíntese do heme, podendo estar associado a diversas outras patologias, tais como desordens abdominais, uso de drogas e intoxicações com metais. Os ataques agudos de CPH são acompanhados por aumentos na excreção urinária de ALA, PBG e uroporfirina, mas ao contrário do observado na PAI, a excreção destes metabólitos normaliza após os ataques. A excreção urinária de precursores do grupo heme é similar na $\mathrm{CPH}$ e PV, mas a predominância de coproporfirina nas fezes é mais sugestiva de $\mathrm{CPH}$, ao contrário de $\mathrm{PV}$ em que as concentrações fecais de coproporfirina e protoporfirina são aproximadamente iguais.

O diagnóstico de PV deve ser proposto em casos de sinais clínicos de porfiria aguda, com atividade normal da PBGD. A atividade da protoporfirinogênio oxidase é medida em fibroblastos ou linfócitos, mas o ensaio geralmente não está disponível. Na sua ausência, a melhor opção para triagem dos membros da família é a determinação das concentrações fecais de porfirinas, sendo geralmente observados níveis de protoporfirina superiores aos de coproporfirina (principalmente o isômero III). No entanto, as porfirinas fecais podem estar pouco elevadas na pré-puberdade ou em idosos heterozigotos. Geralmente, as alterações na excreção urinária de precursores do heme ocorrem apenas durante os ataques. Invariavelmente, o plasma contém uma porfirina com emissão de fluorescência máxima à $626 \pm 1 \mathrm{~nm}$, que parece ser específica para PV. Em pacientes que apresentam somente manifestações cutâneas, a presença de isocoproporfirina e porfirina 8- e 7-carboxilato na urina é geralmente suficiente para diferenciar porfiria cutânea tardia de PV (Tabela I). As con- 
centrações de ALA e PBG ajudam pouco no diagnóstico de PV, exceto na diferenciação de casos de porfiria cutânea tardia.

\section{Alterações genéticas}

A enzima ALA-D (Figura 1) é codificada por um gene localizado no cromossomo 9q34 e organizado em 12 exons (Potluri et al., 1987). Esta enzima exibe polimorfismo genético, apresentando 2 alelos (alelo $1 \mathrm{e}$ alelo 2), o que possibilita a existência de 3 fenótipos enzimáticos distintos (1-1, 1-2 e 2-2) (Wetmur et al., 1991). A seqüência do alelo 2 difere do alelo 1 apenas pela troca do nucleotídeo da posição 177 da região de codificação de G para C (Wetmur et al., 1991), o que resulta na substituição de uma lisina por asparagina na enzima. Quatro casos de porfiria por deficiência da ALA$\mathrm{D}$ foram descritos até o momento (Sassa, 1998). Em todos os pacientes estudados foi observado que um ou ambos os alelos codificam enzimas com atividade reduzida (Sassa, 1998). Os defeitos moleculares observados no gene da ALA-D são apresentados na Tabela II.

A enzima PBGD (Figura 1), cuja deficiência origina a PAI, é codificada por um gene localizado no cromossomo 11q24, que está organizado em 15 exons (Namba et al., 1991). Existem duas isoformas da enzima, uma presente em todos os tecidos e outra presente apenas nos eritrócitos (Deybach, Puy, 1995). Ambas as isoformas são codificadas a partir do mesmo gene, por emenda ("splicing") alternativa. Até o momento, foram identificadas 210 mutações (56 defeitos de emenda, 62 deleções/inserções, 70 mutações de sentido trocado, 21 mutações sem sentido e 1 mutação no promotor) no gene que codifica esta enzima (revisado por Capellini et al.,
2002) impedindo a codificação da proteína pelo alelo mutante (mais usual) ou resultando na síntese de uma proteína estável, mas com atividade catalítica anormal (Grandchamp, 1998). Devido à heterogeneidade dos defeitos genéticos, que afetam esta enzima, é necessário o desenvolvimento de métodos que permitam a análise de todo o gene para que se possa introduzir testes de rotina para triagem do DNA (McDonagh, Bissell, 1998).

A enzima coproporfirinogênio oxidase (Figura 1) é codificada por um gene localizado no cromossomo 3 q12, que está organizado em 7 exons e exibe polimorfismo (Sassa, Kappas, 2000). Mutações no gene que codifica esta enzima são responsáveis pela $\mathrm{CPH}$. A CPH é a porfiria aguda que apresenta maior heterogeneidade genética, pois com exceção de uma mutação, todas as demais observadas até o momento estão restritas a uma única família (Lamoril et al., 2001). As mutações observadas com maior freqüência no gene da coproporfirinogênio oxidase são do tipo sentido trocado (Tabela III).

A enzima protoporfirinogênio oxidase (Figura 1), cuja deficiência está relacionada à PV, é codificada por um gene localizado no cromossomo 1q22-23, que está organizado em 13 exons e apresenta polimorfismo (Kirsch et al., 1998). Diversas mutações no gene que codifica esta enzima já foram identificadas em famílias com porfiria variegada, sendo que a mutação R59W é a responsável pela alta incidência desta doença na África do Sul (Meissner et al., 1996).

Apesar da utilização da análise do DNA no diagnóstico das porfirias agudas ser dificultada pela grande heterogeneidade genética observada nessas desordens, trabalhos recentes têm indicado que a confiabilidade da análise do DNA é superior a das análises bioquímicas (dosagem de metabólitos) (Grandchamp, 1998; Martásek et al.,

TABELA II - Defeitos genéticos na ALA-D de quatro pacientes com porfiria por deficiência da ALA-D

\begin{tabular}{lcccl}
\hline & Alelo & Mutação $^{\#}$ & Modificação na seqüência* $^{*}$ & Referência \\
\hline Paciente 1 & 1 & G820A & A274T & Ishida et al., 1990 \\
Paciente 2 & 2 & G718T & R240W & Ishida et al., 1992 \\
& 1 & - & V153M & Akagi et al., 1992 \\
Paciente 3 & 2 & - & N.D. & \\
& 1 & G397A & G133R & Plewinska et al., 1991 \\
Paciente 4 & 2 & G823A & V275M & Plewinska et al., 1991 \\
& 1 & - & G133R, K59N & Horie et al., 1993 \\
\hline
\end{tabular}

\#Apresentada como a base encontrada no gene normal, sua posição e a base encontrada no gene mutado. *Apresentada como o aminoácido (código padrão de uma letra) encontrado na proteína normal, sua posição e o aminoácido encontrado na proteína defeituosa. N.D. - Não determinado. Fonte: Adaptado de Sassa, 1998. 
TABELA III - Defeitos genéticos na coproporfirinogênio oxidase de alguns pacientes com CPH

\begin{tabular}{|c|c|c|}
\hline$\overline{\text { Mutação }^{\#}}$ & Modificação na seqüência* & Referência \\
\hline $\begin{array}{l}\text { Inserção GCGCA } \\
\text { (posição 129) }\end{array}$ & mutação de quadro de leitura ("frameshift") & Lamoril et al., 1997 \\
\hline Deleção de 21 pb & Deleção de 7 aminoácidos & Lamoril et al., 1997 \\
\hline G565A & G189S & Fujita et al., 1994 \\
\hline G601A & E201K & Schreiber et al., 1997 \\
\hline C745T & $\mathrm{P} 249 \mathrm{~S}$ & Schreiber et al., 1997 \\
\hline C883G & H295D & Lamoril et al., 1997 \\
\hline C991T & R331W & Martásek et al., 1994 \\
\hline A1210G & K404E & Lamoril et al., 1995 \\
\hline $\begin{array}{l}\text { Inserção T } \\
\text { (posição 1268) }\end{array}$ & mutação de quadro de leitura ("frameshift") & Schreiber et al., 1997 \\
\hline G1277A & mutação em sítio de emenda (deleção do exon 6) & Delfau-Larue et al., 1994 \\
\hline G265A & G89S & Sassa et al., 1997 \\
\hline
\end{tabular}

\#Apresentada como a base encontrada no gene normal, sua posição e a base encontrada no gene mutado. *Apresentada como o aminoácido (código padrão de uma letra) encontrado na proteína normal, sua posição e o aminoácido encontrado na proteína defeituosa. Fonte: Adaptado de Martásek, 1998; Sassa et al., 1997.

1998; Fraunberg, Kauppinen, 2000). No entanto, é importante ressaltar que a detecção da mutação não fornece informação quanto à gravidade da doença no paciente, sendo necessárias análises bioquímicas e a anamnese dos pacientes (Kirsch et al., 1998). Além disso, as análises bioquímicas continuam sendo essenciais para realizar o acompanhamento do quadro clínico durante as fases sintomáticas.

\section{AGRADECIMENTOS}

Os autores agradecem o apoio financeiro da Fundação de Amparo à Pesquisa do Estado do Rio Grande do Sul (FAPERGS, processo $n^{\circ} .00 / 1716.8 \mathrm{e} \mathrm{n}^{\circ}$. 02/0102.3) e do Conselho Nacional de Desenvolvimento Científico e Tecnológico (CNPq, processo $\left.\mathrm{n}^{\circ} .463703 / 00-6\right)$ concedidos a T. Emanuelli. C.A. Prauchner foi bolsista de iniciação científica da FAPERGS e atualmente é bolsista de mestrado da CAPES. T. Emanuelli é bolsista pesquisadora do CNPq.

\section{ABSTRACT}

\section{Acute porphyrias: biochemical findings}

Porphyrias are disorders characterized by identical neurological disfunctions arising from an enzymatic defect in the heme biosynthetic pathway. The acute porphyrias, namely 5-aminolevulinic acid dehydratase porphyria, acute intermittent porphyria, hereditary coproporphyria and variegate porphyria are caused respectively by deficiencies in the enzymes 5aminolevulinic acid dehydratase, porphobilinogen deaminase, coproporphyrinogen decarboxilase and protoporphyrinogen oxidase. Acute porphyrias are characterized by an increase of plasma and liquor 5aminolevulinic acid levels, followed by increased urinary excretion of this compound. Increases in the urinary excretion of porphyrins or other porphyrin precursors may be observed depending on the type of acute porphyria. Diagnosis of acute porphyria cases rests on the measurement of porphyrins or porphyrin precursors in urine, blood and faeces. Since the clinical manifestations are generally triggered by ambiental or acquired factors, screenings for gene carriers among relatives of AIP are important to identify latent cases. The diagnosis of gene carriers was usually based on the determination of the activity of blood heme biosynthetic enzymes and more recently on DNA analysis.

UNITERMS: Acute porphyria. 5-Aminolevulinic acid. Porphyrins. Porphobilinogen. Mutations.

\section{REFERÊNCIAS BIBLIOGRÁFICAS}

AKAGI, R., MEGURO, K., DOSS, M. Molecular studies of the gene defect of ALA dehydratase deficiency porphyria: a new point mutation identified in a second German patient. Porphyrins, v. 1, p. 267-272, 1992. 
ANDERSON, K. E. The porphyrias. In: WYNGAARDEN, J. B., SMITH, L. H., BENNETT, J. C., eds. Cecil textbook of medicine. 19. ed. Philadelphia: W.B. Saunders Co., 1992. p. 1126-1132.

BARBOSA, N. B. V., ROCHA, J. B. T., ZENI, G., EMANUELLI, T., BEQUE, M. C., BRAGA, A. L. Effect of organic forms of selenium on deltaaminolevulinate dehydratase from liver, kidney and brain of adult rats. Toxicol. Appl. Pharmacol., v. 149, p. 243253, 1998.

BIRD, T. D., HAMERNYIK, P., NUTTER, J. Y., LABBE, R. F. Inherited deficiency of $\delta$-aminolevulinic acid dehydratase. Am. J. Hum. Genet., v. 31, p. 662-668, 1979.

CAPPELLINI, M. D., MONTEMUROS, F. M., DI PIERRO, E., FIORELLI, G. Hematologically important mutations: acute intermittent porphyria. Blood Cells Mol. Dis., v. 28, p. 5-12, 2002.

COSTA, C. A., TRIVELATO, G. C., DEMASI, M., BECHARA, E. J. H. Determination of 5-aminolevulinic acid in blood plasma, tissues and cell cultures by highperformance liquid chromatography with electrochemical detection. J. Chromatogr., v. 695, p. 245250, 1997.

DELFAU-LARUE, M. H., MARTÁSEK, P., GRANDCHAMP, B. Coproporphyrinogen oxidase: gene organization and description of a mutation leading to exon 6 skipping. Hum. Mol. Genet., v.3, p. 1325-1330, 1994.

DE MATTEIS, F. Toxicological aspects of liver heme biosynthesis. Semin. Hemat., v. 25, p. 321-329, 1988.

DEYBACH, J. C., PUY, H. Porphobilinogen deaminase gene structure and molecular defects. J. Bioenerg. Biomemb., v. 27, p. 197-205, 1995.

ELDER, G. H., HIFT, R. J., MEISSNER, P. N. The acute porphyrias. Lancet, v. 349, p. 1613-1617, 1997.

EMANUELLI, T., ROCHA, J. B. T., PEREIRA, M. E., PORCIÚNCULA, L. O., SOUZA, D. O. Effects of mercuric chloride intoxication and 2,3dimercaptopropanol (BAL) treatment on deltaaminolevulinate dehydratase from brain, kidney and liver of adult mice. Pharmacol. Toxicol., v. 79, p. 136-143, 1996.
FRAUNBERG, M. V. Z., KAUPPINEN, R. Diagnosis of variegate porphyria - hard to get? Scand. J. Clin. Lab. Invest., v. 60, 605-610, 2000.

FUJITA, H., KONDO, M., TAKETANI, S., NOMURA, N., FURUYAMA, K., AKAGI, R., NAGAI, T., TERAJIMA, M., GALBRAITH, R. A., SASSA, S. Characterization and expression of cDNA encoding coproporphyrinogen oxidase from a patient with hereditary coproporphyria. Hum. Mol. Genet., v. 3, p. 1807-1810, 1994.

GALBRAITH, R. A., SASSA, S., KAPPAS, A. A comparison of the utility of Dowex resin and polybenzimidazole Aurorez resin in the determination of urinary porphobilinogen concentrations. Clin. Chim. Acta, v. 164, p. 235-239, 1987.

GRANDCHAMP, B. Acute intermittent porphyria. Semin. Liver Dis., v. 18, p. 17-24, 1998.

GRANICK, S., VAN DEN SCHRIECK, H. G. Porphobilinogen and d-aminolevulinic acid in acute porphyria. Proc. Soc. Exp. Biol. Med., v. 88, p. 270-273, 1955.

GROSS, U., SASSA, S., JACOB, K., DEYBACH, J. C., NORDMANN, Y., FRANK, M., DOSS, M. O. 5 Aminolevulinic acid dehydratase deficiency porphyria: a twenty-year clinical and biochemical follow-up. Clin. Chem., v. 44, p. 1892-1896, 1998.

HORIE, Y., MEGURO, K., FUJITA, H. Molecular analysis of the gene defects of ALA dehydratase deficiency porphyria developed in an elderly patient. Porphyrins, v. 2, p. 143-148, 1993.

ISHIDA, N., FUJITA, H., NOGUCHI, T., DOSS, M., KAPPAS, A., SASSA, S. Message amplification phenotyping of an inherited d-aminolevulinate dehydratase deficiency in a family with acute hepatic porphyria. Biochem. Biophys. Res. Commun., v. 172, p. 237-242, 1990.

ISHIDA, N., FUJITA, H., FUKUDA, Y., NOGUCHI, T., DOSS, M., KAPPAS, A., SASSA, S. Cloning and expression of the defective genes from a patient with daminolevulinate dehydratase porphyria. J. Clin. Invest., v. 89, p. 1431-1437, 1992. 
KAPPAS, A., SASSA, S., GALBRAITH, R. A., NORDMANN, Y. The porphyrias. In: SCRIVER, C. R., BEAUDET, A. L., SLY, W. S., VALLE, D., eds. The metabolic bases of inherited disease. 7. ed. New York: McGraw Hill, 1995. p. 2103-2160.

KIRSCH, R. E., MEISSNER, P. N., HIFT, R. J. Variegate porphyria. Semin. Liver Dis., v. 18, p. 33-41, 1998.

KRIJT, J., STRANSKA, P., MARUNA, P., VOKURKA, M., SANITRAK, J. Herbicide-induced experimental variegate porphyria in mice: tissue porphyrinogen accumulation and response to porphyrinogenic drugs. Can. J. Physiol. Pharmacol., v. 75, p. 1181-1187, 1997.

LAMORIL, J., MARTÁSEK, P., DEYBACH, J. C., DA SILVA, V., GRANDCHAMP, B., NORDMANN, Y. A molecular defect in coproporphyrinogen oxidase gene causing harderoporphyria, a variant form of hereditary coproporphyria. Hum. Mol. Genet., v. 4, p. 275-278, 1995.

LAMORIL, J., DEYBACH, J. C., PUY, H., GRANDCHAMP, B., NORDMANN, Y. Three novel mutations in the coproporphyrinogen oxidase gene. Hum. Mutat., v. 9, p. 78-80, 1997.

LAMORIL, J., PUY, H., WHATLEY, S. D., MARTIN, C., WOLLF, J. R., DA SILVA, V., DEYBACH, J. C., ELDER, G. H. Characterization of mutations in the CPO gene in British patients demonstrates absence of geneotype-phenotype correlation and identifies relationship between hereditary coproporphyria and harderoporphyria. Am. J. Hum. Genet., v. 68, p. 11301138, 2001.

MARTÁSEK, P. Hereditary coproporphyria. Semin. Liver Dis., v. 18, p. 25-32, 1998.

MARTÁSEK, P., NORDMANN, Y., GRANDCHAMP, B. Homozygous hereditary coproporphyria caused by an arginine to tryptophan substitution in coproporphyrinogen oxidase and common intragenic polymorphisms. Hum. Mol. Genet., v. 3, p. 477-480, 1994.

MAUZERALL, D., GRANICK, S. The occurance and determination of d-aminolevulinic acid and porphobilinogen in urine. J. Biol. Chem., v. 219, p. 435$446,1956$.
McCOLL, K.E.L., WALLACE, A. M., MOORE, M.R. Alterations in haem biosynthesis during human menstrual cycle: studies with normal subjects and patients with latent and active, acute intermittent porphyria. Clin. Sci., v. 62, p. 183-191, 1982.

McDONAGH, A. F., BISSELL, D. M. Porphyria and porphyrinology - The past fifteen years. Semin. Liver Dis., v. 18, p. 3-15, 1998.

MEISSNER, P. N., DAILEY, T. A., HIFT, R. J., ZIMAN, M., CORRIGALL, A. V., ROBERTS, A. G., MEISSNER, D. M., KIRSCH, R. E., DAILEY, H. A. A R59W mutation in human protoporphyrinogen oxidase results in decreased enzyme activity and is prevalent in South Africans with variegate porphyria. Nat. Genet., v. 13, p. 95-97, 1996.

MEYER, U. A., SCHURMANS, M. M., LINDBERG, R. L. P. Acute porphyrias: pathogenesis of neurological manifestations. Semin. Liver Dis., v. 18, p. 43-52, 1998.

MOORE, M. R. International review of drugs in acute porphyria. Int. J. Biochem., v. 12, p. 1089-1097, 1980.

MOORE, M. R. Laboratory investigation of disturbances of porphyrin metabolism. London: Association of Clinical Pathologists, 1983.118 p.

MOORE, M. R. Biochemistry of porphyrias. Int. J. Biochem., v. 25, p. 1353-1368, 1993.

NAMBA, M., NARAHARA, K., TSUJ, K., YOKOYAMA, Y., SEINO, Y. Assignment of human PBGD to 11q24.1 ${ }^{\circledR}$ 11q24.2 by in situ hybridization and gene dosage studies. Cyto. Cell Genet., v. 67, p. 105-108, 1991.

OISHI, H., NOMIYAMA, H., NOMIYAMA, K., TOMOKUNI, K. Fluorometric HPLC determination of delta-aminolevulinic acid (ALA) in the plasma and urine of lead workers: biological indicators of lead exposure. J. Anal. Toxicol., v. 20, p. 106-110, 1996.

PERLROTH, M. G., TSCHUDY, D. K., WAXMAN, A., ODELL, W. D. Abnormalities of growth hormone regulation in acute intermittent porphyria. Metabolism, v. 16, p. 87-90, 1967. 
PLEWINSKA, M., THUNELL, S., HOLMBERG, L., WETMUR, J. G., DESNICK, R. J. $\delta$-Aminolevulinate dehydratase deficient porphyria: Identification of the molecular lesions in a severely affected homozygotes. Am. J. Hum. Genet., v. 49, p. 167-174, 1991.

POTLURI, V. R., ASTRIN, K. H., WETMUR, J. G., BISHOP, D. F., DESNICK, R. J. Human 5aminolevulinate dehydratase: Chromosomal localization to $9 \mathrm{q} 34$ by in situ hybridization. Hum. Genet., v. 76, p. 236- 239, 1987.

PUY, H., DEYBACH, J. C., BEAUDRY, P., CALLEBERT, J., TOUITOU, Y., NORDMANN, Y. Decreased nocturnal plasma melatonin levels in patients with recurrent acute intermittent porphyria attacks. Life Sci., v. 53, p. 621-627, 1993.

ROCHA, J. B. T., FREITAS, A. J., MARQUEZ, M. B., PEREIRA, M. E., EMANUELLI, T., SOUZA, D. O. Effects of methylmercury exposure during the second stage of rapid postnatal brain growth on deltaaminolevulinate dehydratase (E.C. 4.2.1.24) of suckling rats. Braz. J. Med. Biol. Res., v. 26, p. 1077-1083, 1993.

ROCHA, J. B. T., PEREIRA, M. E., EMANUELLI, T., CHRISTOFARI, R. S., SOUZA, D. O. Effects of mercury chloride and lead acetate treatment during the second stage of rapid postnatal brain growth on ALA-D activity in brain, liver, kidney and blood of suckling rats. Toxicology, v. 100, p. 27-37, 1995.

SASSA, S. ALAD porphyria. Semin. Liver Dis., v. 18, p. $95-$ 101, 1998.

SASSA, S., KAPPAS, A. Molecular aspects of the inherited porphyrias. J. Int. Med., v. 247, p. 169-178, 2000.
SASSA, S., KONDO, M., TAKETANI, S., NOMURA, N., FURUYAMA, K., AKAGI, R., NAGAI, T., TERAJIMA, M., GALBRAITH, R. A., FUJITA, H. Molecular defects of the coproporphyrinogen oxidase gene in hereditary coproporphyria. Cell Mol. Biol., v. 43, p. 59-66, 1997.

SCHREIBER, W. E., ZHANG, X., SENZ, J., JAMANI, A. Hereditary coproporphyria: exon screening by heteroduplex analysis detects three novel mutations in the coproporphyrinogen oxidase gene. Hum. Mutat., v. 10, p. 196-200, 1997.

TISHLER, P. V., WOODWARD, B., O'CONNOR, J., HOLDBROOK, D. A., SEIDMAN, L. J., HALLET, M., KNIGHTON, D. J. High prevalence of intermittent acute porphyria in a psychiatric patient population. Am. $J$. Psych., v. 142, p. 1430-1436, 1985.

TSCHUDY, D. P., VALSAMIS, M., MAGNUSSEN, C. R. Acute intermittent porphyria: clinical and selected research aspects. Ann. Int. Med., v. 83, p.851, 1975.

WAXMAN, A. D., BERK, P. D., SCHALCH, D., TSCHUDY, D. P. Isolated adrenocorticotrophic hormone deficiency in acute intermittent porphyria. Ann. Int. Med., v. 70, p. 317-323, 1969.

WETMUR, J. G., KAYA, A. H., PLEWINSKA, M. Molecular characterization of the human daminolevulinate dehydratase 2 (ALAD2) allele: Implications for molecular screening of individuals for genetic susceptibility to lead poisoning. Am. J. Hum. Genet., v. 49, p. 757 - 763, 1991.

YEUNG LAIWAH, A. C., MOORE, M. R., GOLDBERG A. Pathogenesis of acute porphyria. Q. J. Med., v. 241, p. 377-392, 1987.

Recebido para publicação em 19 de março de 2001. 